\title{
Numerical Study of Natural Convection in a Porous Square Enclosure with Sinusoidally Varying Temperature Profile on the Bottom Wall
}

\author{
Alhadj Hisseine Issaka Ali'1,2, Samba Dia1, Mahamoud Y. Khayal ${ }^{3}$, Cheikh Mbow ${ }^{1}$, \\ Aboubaker Chedikh Beye ${ }^{1}$ \\ ${ }^{1}$ Department of Physics, Cheikh Anta University Diop of Dakar, Dakar, Senegal \\ ${ }^{2}$ Department of Hydrocarbons Exploitation, Higher National Petroleum Institute of Mao, Mao, Chad \\ ${ }^{3}$ Department of Technical Sciences, University of N'Djamena, N'Djamena, Chad \\ Email: elhadj_hissen@yahoo.fr
}

How to cite this paper: Ali, A.H.I., Dia, S., Khayal, M.Y., Mbow, C. and Beye, A.C. (2017) Numerical Study of Natural Convection in a Porous Square Enclosure with Sinusoidally Varying Temperature Profile on the Bottom Wall. Open Journal of Fluid Dynamics, 7, 263-275.

https://doi.org/10.4236/ojfd.2017.73017

Received: July 28, 2017

Accepted: September 4, 2017

Published: September 7, 2017

Copyright $\odot 2017$ by authors and Scientific Research Publishing Inc. This work is licensed under the Creative Commons Attribution International License (CC BY 4.0).

http://creativecommons.org/licenses/by/4.0/

(c) (i) Open Access

\begin{abstract}
This current study focuses on the simulation of natural convection in square cavity filled with a porous medium considered homogenous, isotropic and saturated by a Newtonian fluid obeying the law of Darcy and the hypothesis of Boussinesq. The lower horizontal wall of the enclosure is subjected to a temperature varying sinusoidally with the space while the upper horizontal wall is maintained adiabatic. The vertical walls are kept cold isotherm. In order to generalize the results, all governing equations are put into dimensionless form, discretized by the Finite Difference Method and solved by the relaxed Gauss Seidel (SUR) Algorithm. A code has been proposed in Fortran 95, in order to solve numerically the equations of the problem. The study parameters are the Rayleigh-Darcy number $(\mathrm{Ra})$ and the amplitude $\left(\mathrm{A}_{\mathrm{r}}\right)$ of the hot wall temperature. The effects of the Rayleigh-Darcy number and amplitude on the dynamic and thermal field, the horizontal velocity distribution and the mean horizontal temperature distribution $(y=0.5)$ were presented and discussed. It emerges from this study that the increases of the amplitude and Rayleigh-Darcy number intensify the flow and the global transfer of heat in our physical domain.
\end{abstract}

\section{Keywords}

Natural Convection, Porous Media, Numerical Method, Sinusoidal Temperature

\section{Introduction}

Nowadays convection transfer in a porous medium saturated by a fluid is a pa- 
ramount importance in the field of engineering and Physics. Its applications are encountered in several fields such as geothermal energy, oil recovery, solar energy storage systems, transport of pollutants into a soil and storage chemicals materials to name but a few.

The problem of convection in fluid saturated porous media has been widely studied in the past decades for its applications in thermal, electronics, and engineering [1]-[17]. The problem of natural convection in a porous cavity whose walls are maintained at different temperatures or heat fluxes is classic problem in porous media. Numerous research projects, both theoretical and experimental, have been carried out on this type of cavity [1]. The literature on natural Convection in porous media is abundant. An excellent review of these studies can be found in the books of Nield and Bejan [2], Kaviany (2004) [3], Vafai (2005) [4], Ingham and Pop [5] search field.

However, few studies on natural convection in porous media with variable heating have been conducted throughout the world. Schaladow et al. (1989) [6] studied natural convection in the case where a cavity is subjected to a temperature varying linearly with time. Their results show that the dynamic and thermal fields are very little affected by this type of boundary conditions. Saied et al. [1] studied natural convection in a porous cavity with sinusoidal heating of the lower horizontal wall, cooling of the upper horizontal wall and vertical adiabatic walls. This study showed that overall heat transfer improves with the length of the heated part and the amplitude of the temperature. Oztop et al. [7] have made a numerical study of the magneto-convection in a non-isothermal heating enclosure. They observed that the transfer increases when the amplitude of the temperature increases and decreases with the number of Hartmann. Kalabin et al. [8] have studied the convective transfer in a square inclined cavity subjected to a variable temperature on its right vertical wall. They found that the heat transfer was maximal for an inclination equal to 54 degrees and for a non-dimensional frequency $f=20$. Kazmierczak et al. [9] analyzed the effect of a temperature varying sinusoidally over time on heat transfer and fluid flow in square cavity. They showed that the mean transfer is almost insensitive to the variation of the period. Varol et al. [10] analyzed the natural convention in a porous medium with a horizontal temperature varying sinusoidally while other walls are maintained adiabatic. They found that the transfer rate increases with the amplitude of the temperature and decreases with the aspect factor. Deng et al. [11] carried out numerical study of convection in a rectangular enclosure with temperatures of the vertical walls varying sinusoidally. They found that non-uniform heating improves heat transfer by uniform heating.

The main objective of this work is to continue to enrich this kind of problem by conducting a numerical study of natural convection in a porous square cavity saturated by a Newtonian fluid whose lower horizontal wall of the enclosure is totally subjected to Temperature varying sinusoidally with the space whereas the upper horizontal wall is maintained adiabatic (Figure 1). The vertical walls are 


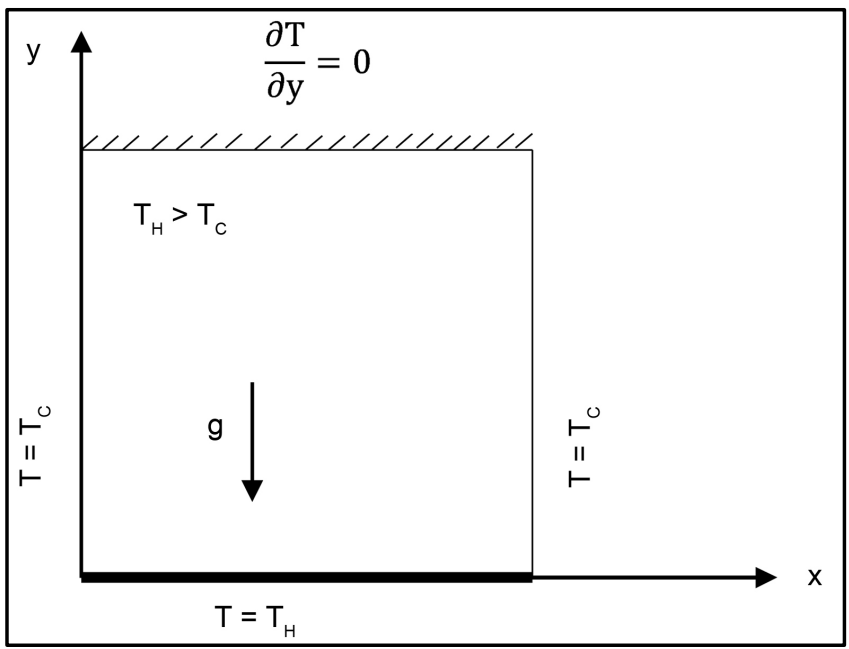

Figure 1. Schematic diagram of the physical model and coordinate system.

kept cold isotherm. This study is very important because this kind of temperature variation occurs in the applications when a cylindrical heater is placed on a flat wall. The influence of the amplitude on the one hand on the thermal and dynamic fields and on the temperature and velocity distributions of the mean horizontal plane $(y=0.5)$ on the other hand has been investigated for a best control of convection in our cavity.

\section{Materials and Methods}

\subsection{Mathematical Formulation}

The system studied here is a porous square cavity saturated with a Newtonian fluid. The lower horizontal wall of the enclosure is subjected to a temperature varying sinusoidally with the space while the upper horizontal wall is maintained adiabatic. The vertical walls are kept cold isotherm. The simplifying assumptions adopted are as follows:

1) The flow is laminar and two-dimensional and follows the law of Darcy;

2) The porous medium saturated by the fluid is assumed to be homogeneous and in thermal equilibrium.

$$
\begin{gathered}
\Delta \boldsymbol{v}=0 \\
\boldsymbol{v}=-\frac{K}{\mu_{f}}\left(\nabla p-\rho_{f} \boldsymbol{g} \boldsymbol{e}_{z}\right) \\
(\rho c)^{*} \frac{\partial T}{\partial t}+(\rho c)_{f}(\boldsymbol{v} \cdot \nabla) \boldsymbol{T}=\nabla\left(\lambda^{*} \nabla T\right) \\
(\rho c)^{*}=\varphi(\rho c)_{f}+(1-\varphi)(\rho c)_{s}
\end{gathered}
$$

Under the boundary conditions are as follows:

$$
\begin{aligned}
& u(0, y)=0, v(0, y)=0, T(0, y)=0, u(H, y)=0, \\
& v(H, y)=0, T(H, y)=0
\end{aligned}
$$




$$
\begin{gathered}
u(x, 0)=0, v(x, 0)=0, T(x, 0)=0, u(x, H)=0, v(x, H)=0, \\
T_{H}(x, 0)=T_{H}+A_{r}\left(T_{H}-T_{C}\right) \cos \left(\frac{\pi x}{H}\right), \partial T(x, H) / \partial x=0
\end{gathered}
$$

Equations (1)-(3) can be written in terms of stream function (5)-(6) by positing:

$$
\begin{gathered}
u=\frac{\partial \psi}{\partial y}, v=-\frac{\partial \psi}{\partial x} \\
x^{*}=\frac{x}{H}, y^{*}=\frac{y}{H}, t^{*}=\frac{t}{\frac{H^{2}(\rho c)^{*}}{\lambda^{*}}}, \\
t_{0}=\frac{H^{2}(\rho c)^{*}}{\lambda^{*}}, T^{*}=\frac{T-T_{0}}{T_{w}-T_{0}}, v^{*}=\frac{\boldsymbol{V}}{\frac{\lambda^{*}}{H(\rho c)_{f}}}, \\
P^{*}=\frac{P+\rho_{0} g z}{\lambda^{*} \mu_{f}}, \psi^{*}=\frac{\psi}{K^{*}(\rho c)_{f}} \\
\frac{\partial^{2} \psi^{*}}{\partial x^{* 2}}+\frac{\partial^{2} \psi^{*}}{\partial y^{* 2}}=-R a\left(\frac{\partial T^{*}}{\partial x^{*}}\right) \\
\frac{\partial T^{*}}{\partial t^{*}}+\frac{\partial \psi^{*}}{\partial y^{*}} \frac{\partial T^{*}}{\partial x^{*}}-\frac{\partial \psi^{*}}{\partial x^{*}} \frac{\partial T^{*}}{\partial y^{*}}=\nabla^{2} T^{*}
\end{gathered}
$$

where the Darcy-Rayleigh number is defined by:

$$
R a=\frac{g \beta K\left(T_{H}-T_{C}\right)}{\alpha v}
$$

with: $\alpha=\frac{\lambda^{*}}{(\rho c)_{f}}$

The Boundary Conditions (5)-(6) become:

$$
\begin{gathered}
y^{*}=0,0 \leq x^{*} \leq 1: T^{*}\left(0, x^{*}\right)=1+A_{r} \cos \left(\pi x^{*}\right), \psi^{*}=0 \\
y^{*}=1,0 \leq x^{*} \leq 1: \frac{\partial T^{*}}{\partial y^{*}}=0, \psi^{*}=0 \\
x^{*}=1,0 \leq y^{*} \leq 1: T^{*}=0, \psi^{*}=0 \\
x^{*}=0,0 \leq y^{*} \leq 1: T^{*}=0, \psi^{*}=0
\end{gathered}
$$

\subsection{Heat Transfer}

An important physical quantity in heat transfer is the Nusselt number, which is defined by the flux transferred in convection on the flux transferred in conduction state.

The local number of Nusselt at a bottom wall heated by a variable temperature is defined as follows: 


$$
N u=\frac{1}{\Delta T^{*}}\left(-\frac{\partial T^{*}}{\partial y^{*}}\right)_{y^{*}=0}
$$

The average Nusselt number is given by the following formula:

$$
\overline{N u}=\int_{0}^{1} N u \mathrm{~d} x^{*}
$$

\subsection{Numerical Procedure}

The differential Equations (9) and (10) governing the physical situation are translated into Algebraic equations using the finite difference scheme centered and accurate on the second order. The system of dimensionless algebraic equations with boundary conditions associated (13a)-(13d) is iteratively solved by the relaxed Gauss seidel algorithm. A mesh size of $120 \times 121$ was selected. We have developed a numerical code with FORTRAN 95.

The same convergence criterion is imposed in terms of relative error for temperature and stream function. The calculation stopped when the follows inequalities were satisfied:

$$
\begin{gathered}
\operatorname{Max}\left[\frac{\sum\left|\psi_{i, j}^{n+1}-\psi_{i, j}^{n}\right|}{\sum\left|\psi_{i, j}^{n+1}\right|}\right] \leq 10^{-5} \\
\operatorname{Max}\left[\frac{\sum\left|T_{i, j}^{* n+1}-T_{i, j}^{* n}\right|}{\sum\left|T_{i, j}^{* n+1}\right|}\right] \leq 10^{-5}
\end{gathered}
$$

\section{Results and Discussions}

\subsection{Validation of the Code}

Table 1 Comparison of average Nusselt number with the results of this study A sensitivity test allowed us to choose a uniform mesh size of $121 \times 120$ and the time step used is $10^{-4}$. The results provided by the present complete code solving the problem of natural convection in porous media have been confronted with the results obtained from the work of Manole and Lage (1999), Bejan (1979), and Baytas and pop (2002), for a stationary state of convection in a porous cavity saturated by a Newtonian fluid and whose vertical walls are active (The left vertical wall is heated by a constant temperature while the vertical wall on the right is cooled with a constant temperature) while the horizontal ones are insulated.

Table 1. Comparison of average Nusselt number with the results of this study.

\begin{tabular}{cccc}
\hline \multirow{2}{*}{ Authors } & \multicolumn{3}{c}{ Average Nusselt number } \\
\cline { 2 - 4 } & $\mathrm{Ra}=10$ & $\mathrm{Ra}=100$ & $\mathrm{Ra}=1000$ \\
\hline Manole and Lage (1999) [15] & - & 3.118 & 13.637 \\
Bejan (1979) [17] & - & 4.2 & 15.8 \\
Baytas and Pop (2002) [12] & 1.079 & 3.16 & 14.06 \\
Present study & $\mathbf{1 . 0 7 6 6}$ & $\mathbf{3 . 1 5 7}$ & $\mathbf{1 5 . 8 8}$ \\
\hline
\end{tabular}


Table 1 compares the average Nusselt number on the left hot wall for three Darcy-Rayleigh numbers $(10,100$, and 1000) with the previous work cited above. The results obtained by the present code, in the case where the side walls are active while those horizontal are maintained adiabatic, are in very good agreement with the above-mentioned authors.

\subsection{Effect of Darcy-Rayleigh Number}

The evolution of the thermal and dynamic field in our enclosure is shown Figure 2 for the following Rayleigh numbers: $\mathrm{Ra}=20,100,500$, and 1000 . In each
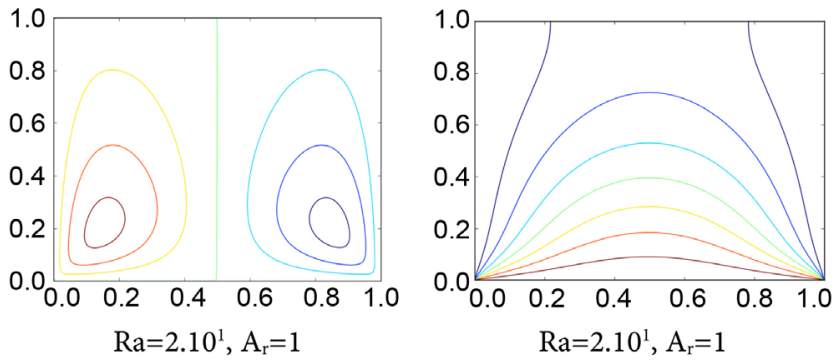

$\mathrm{Ra}=2.10^{1}, \mathrm{~A}_{\mathrm{r}}=1$

$\mathrm{Ra}=2.10^{1}, \mathrm{~A}_{\mathrm{r}}=1$

$\psi_{\max }=0.8228, \psi_{\min }=-0.826$
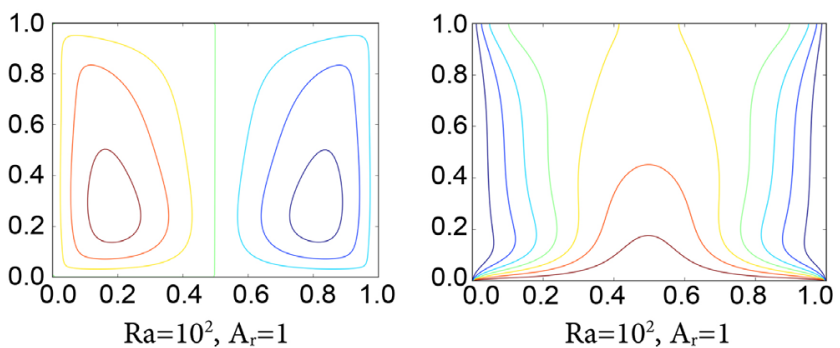

$\psi_{\max }=5.167, \psi_{\min }=-5.152$
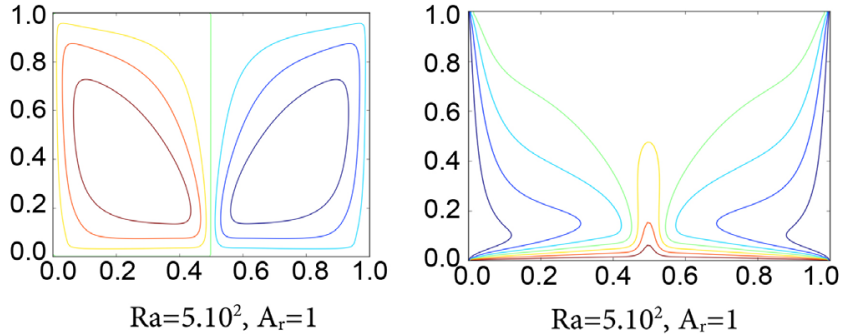

$\psi_{\max }=19.0183, \psi_{\min }=-18.986$
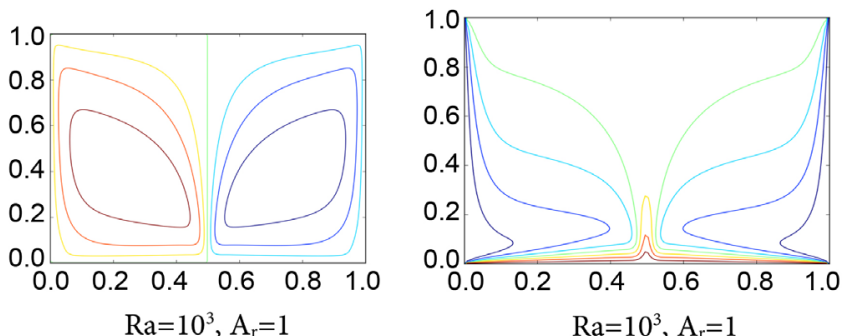

Figure 2. Streamlines (left) and isotherms (right) for $A_{r}=1$ and $\mathrm{Ra}=20,100,500$ and 1000 at steady solution. 
case, the fluid ascends along the vertical axis of symmetry from the middle of the hot wall and then comes into contact with the adiabatic wall which horizontally orientates its movement towards the cool isothermal vertical walls, the fluid descends along the Cold vertical isothermal walls and then goes to the center of the hot wall to complete the first cycle and start another cycle. The rights cells rotate clockwise while the left ones rotate in the opposite direction. However, there is a slight difference in flow intensity due to the spatial variation of the temperature of the hot horizontal wall. When the Rayleigh number is low $(\mathrm{Ra}=$ 100), the flow convection is insignificant. Therefore, heat transfer is dominated by diffusion and isotherms tend to conform to the geometry of the enclosure. The maximum steam function values for $\mathrm{Ra}=2.10^{1}, 10^{2}, 5.10^{2}, 10^{3}$ are respectively equal to: $0.8228 .5 .167,19.0183$, and 28.2869 . It is observed that when the number of Rayleigh increases, the flow becomes more intense and is materialized by a high concentration of the streamlines in the cold walls.

\subsection{Amplitude Effect on the Dynamic and Thermal Fields}

The isotherms and the streamlines with a fixed Rayleigh number $(\mathrm{Ra}=100)$ for different amplitudes are shown in Figure 3 when the amplitude is equal to zero, we observed that the viscous forces outweigh those of flotation and therefore the heat transfer highly diffusive. As the amplitude increases, the heat transfer increases and materialized by an even greater stratification of the isotherms in the cold isothermal walls, the amplitude being high. On the other hand, the greater the value of the stream function, the greater the amplitude. Indeed for these values taken by the amplitude $\left(A_{r}=0,0.6,1\right)$, the maximums of stream function values are respectively equal to: $2.403,4.08607,5.167$.

\subsection{Amplitude Effect on the Temperature at Horizontal Plane $(y=0.5)$}

Figure 4 shows the temperature evolution on the mean horizontal plane $(y=$ $0.5)$ for a fixed Rayleigh number $\left(\mathrm{Ra}=10^{2}\right)$. The temperature on the horizontal plane on the mean plane $(\mathrm{y}=0.5)$ has a Parabolic profile for $\mathrm{Ra}=100$ and reaches his maximum at the point of abscissa $\mathrm{x}$ equal to 0.5 . This maximum reached by temperature increases as the amplitude of the temperature on the horizontal wall increases.

We have remarked that for $\mathrm{Ra}=500, \mathrm{Ra}=1000$, the temperature profile is not parabolic. The maximum reached by the temperature decreases as the Rayleigh number increase.

\subsection{Amplitude Effect on the Velocity at Horizontal Plane $(y=0.5)$}

Figure 5 shows the evolution of the horizontal component of the velocity on the mean horizontal plane $(y=0.5)$ for a fixed Rayleigh number $\left(\mathrm{Ra}=10^{2}\right)$. That the amplitude of the temperature is great. In addition, there is a shift towards the interior of the cell of the extremum cell with the increase of the amplitude of the temperature (Ar). However, we have observed two local maxima for $\mathrm{Ra}=100$ 


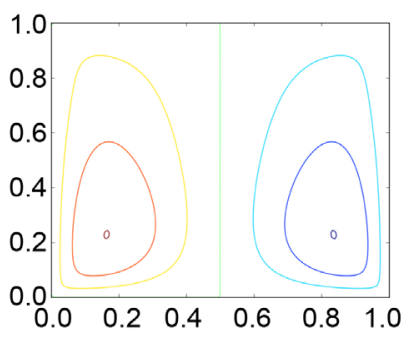

$\mathrm{Ra}=10^{2}, \mathrm{Ar}=0$

$\psi \max =2.403, \psi \min =-2.403$

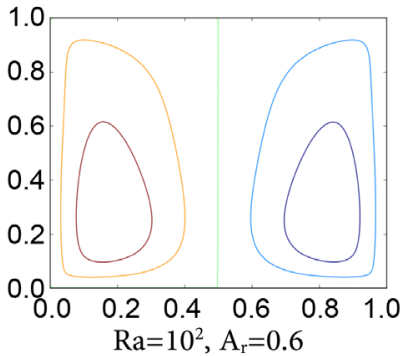

$\psi_{\max }=4.08607, \psi \min =-4.07731$
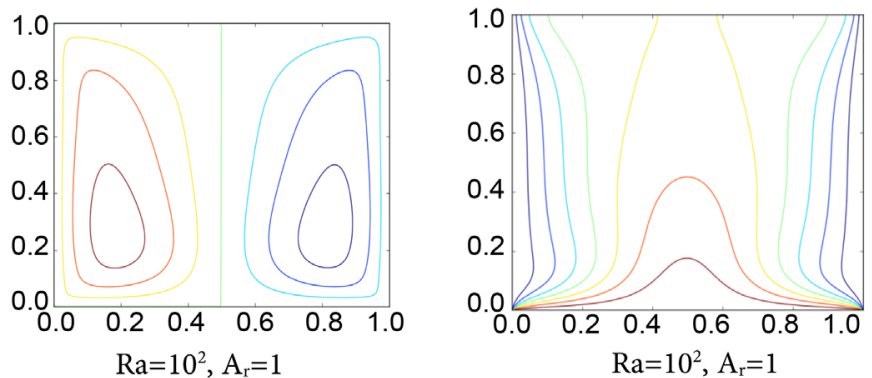

Figure 3. Streamlines (left) and isotherms (right) for $\mathrm{Ra}=100$ and $\mathrm{A}_{\mathrm{r}}=0,0.6,1$ at steady solution.

while the number of Local maxima is equal to four for $\mathrm{Ra}=500$ and $\mathrm{Ra}=1000$.

\subsection{Amplitude Effect on the Global Heat Transfer}

Figure 6 shows the evolution of the mean Nusselt number as a function of the Rayleigh number for different amplitudes. For a fixed amplitude, the average Nusselt number increases as the number of Rayleigh increases. Similarly, for a fixed value of Rayleigh (Ra), the number of Nusselt is as important as the amplitude is high. Thus, increasing the amplitude in the range of amplitude and that of selected Rayleigh numbers improves the transfer global at bottom wall. It is also observed that the effect of the amplitude is greater when the Rayleigh-Darcy number is large.

\section{Conclusion}

In the present paper, we have carried out a numerical study of natural convection in a square cavity filled with a porous medium and saturated by an incompressible Newtonian fluid. The lower horizontal wall of the enclosure is subjected 


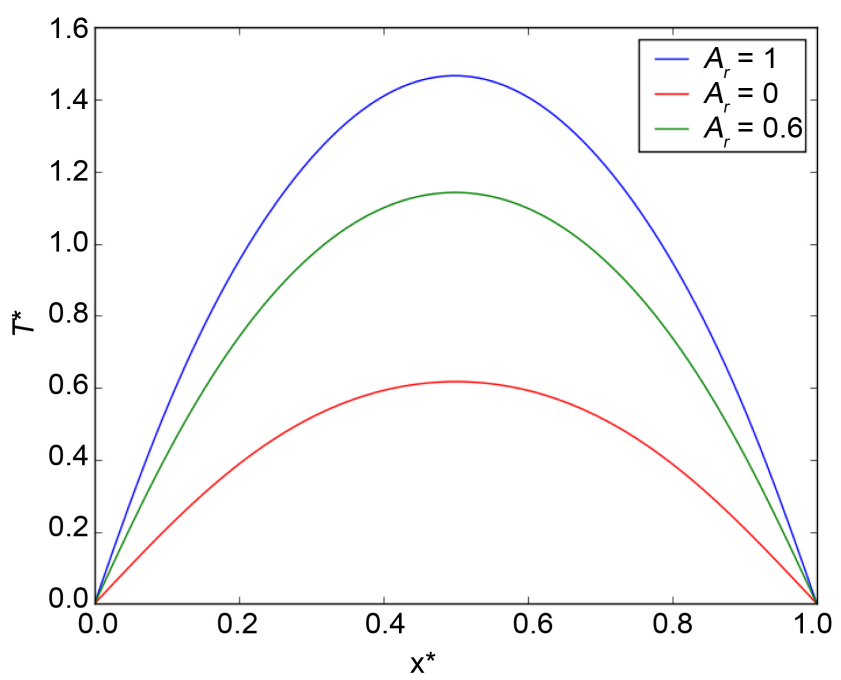

(a)

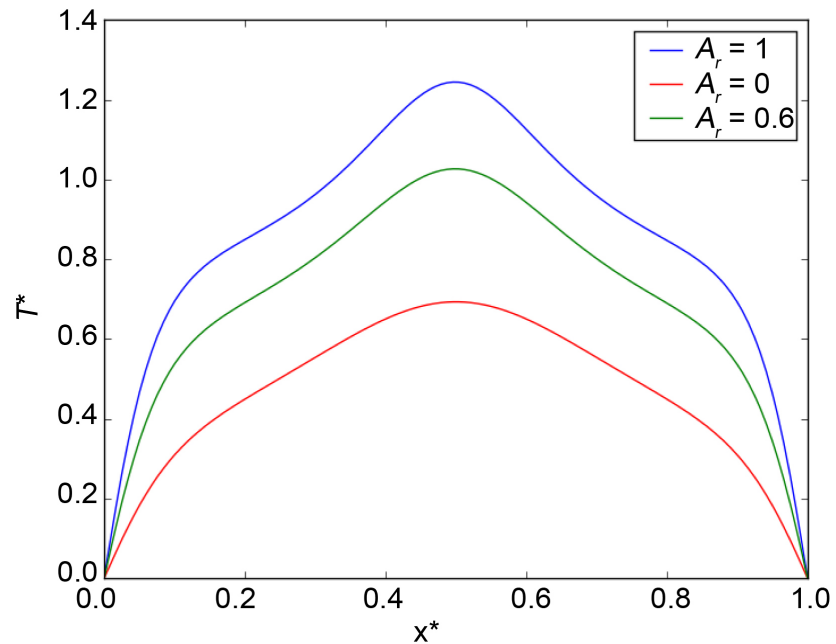

(b)

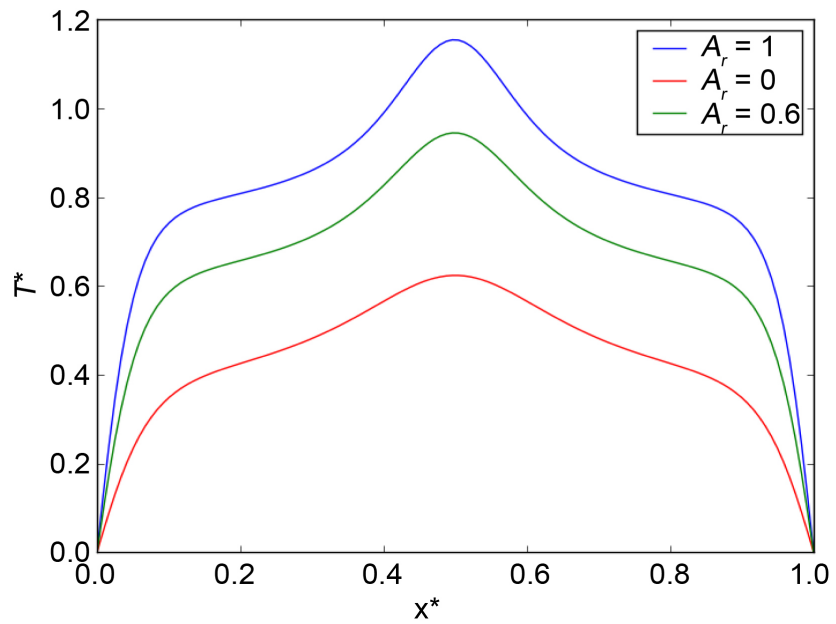

(c)

Figure 4. Spatial variation of temperature at middle horizontal plane for $\mathrm{Ra}=100,500$, and 1000 with $\mathrm{A}_{\mathrm{r}}=0,0.6,1$ at steady solution. (a) $\mathrm{Ra}=100$; (b) $\mathrm{Ra}=500$; (c) $\mathrm{Ra}=1000$. 


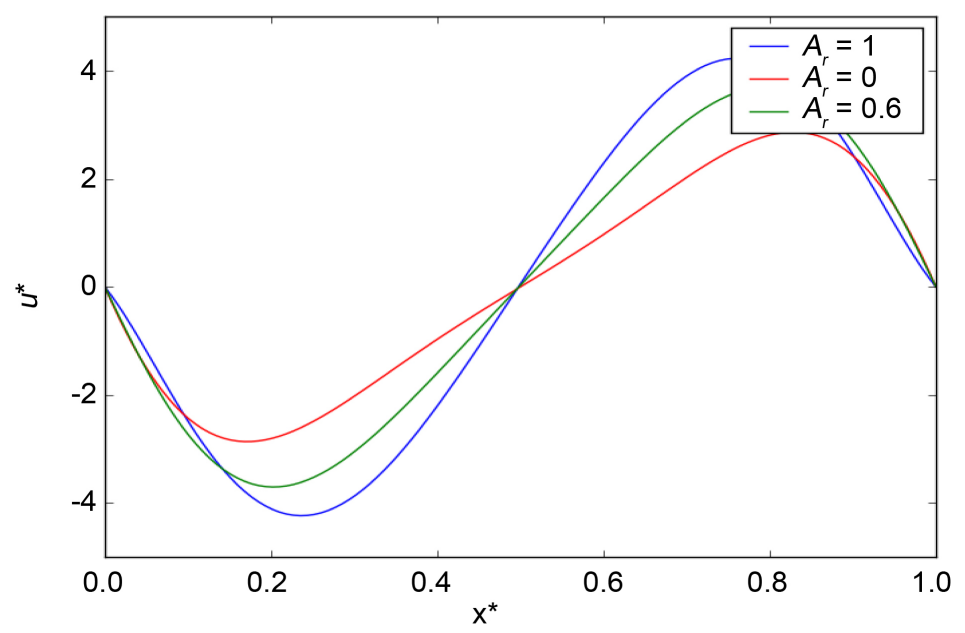

(a)

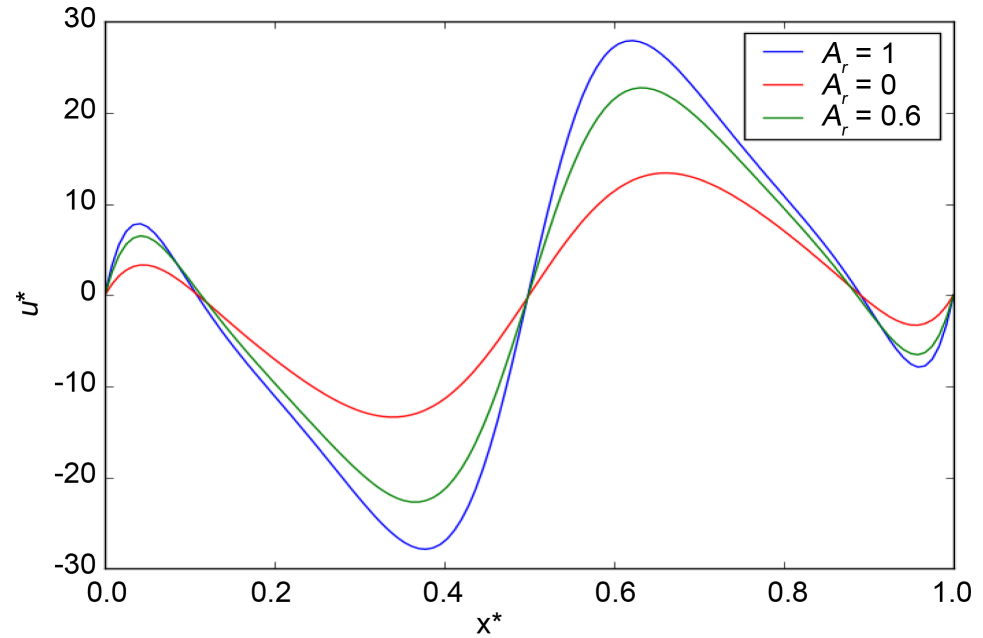

(b)

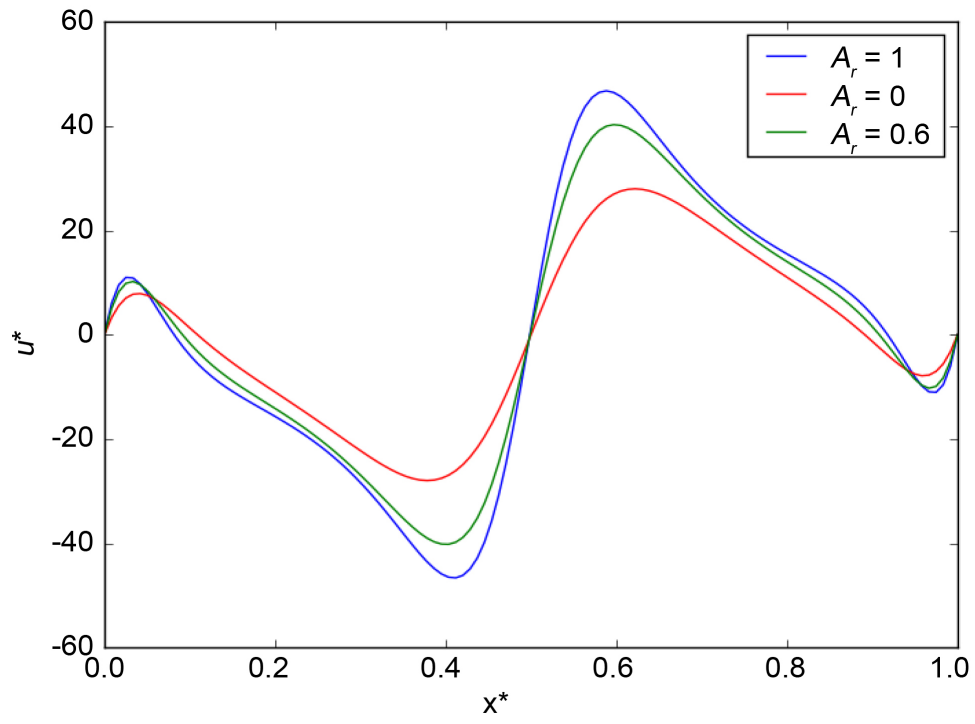

(c)

Figure 5. Velocity for $\mathrm{Ra}=100,500$ and 1000 with $\mathrm{A}_{\mathrm{r}}=0,0.6,1$ at steady solution. (a) $\mathrm{Ra}=100$; (b) $\mathrm{Ra}=500$; (c) $\mathrm{Ra}=1000$. 


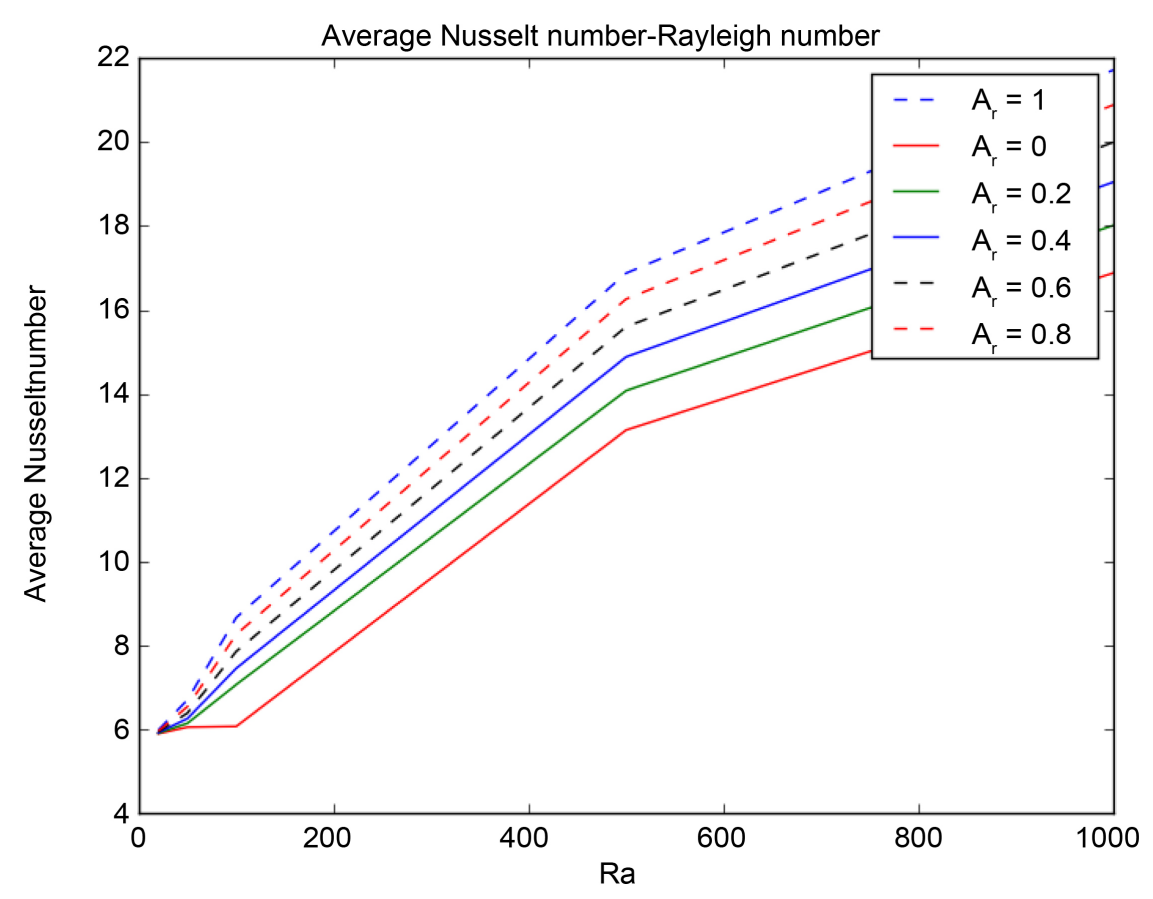

Figure 6. Average Nusselt number variation at horizontal bottom wall against Rayleigh-Darcy number for different amplitudes.

to a temperature varying sinusoidally in space while the upper horizontal wall is maintained adiabatic. The vertical walls are kept cold isotherm. The mathematical model used is that of Darcy with the Boussinesq approximation. The results produced by our calculation code were compared with some results available in the literature; a very good agreement was found between them. The results show that the overall heat transfer rate and the flow intensity increase as the Rayleigh-Darcy number increases in the selected Rayleigh range for fixed temperature amplitude. Similarly, for a fixed Rayleigh number, the overall heat transfer rate and the maximum achieved by the horizontal component of the velocity and the temperature on the mean horizontal plane $(y=0.5)$ increase as the amplitude of temperature increases in the chosen range of amplitudes. The results obtained in this study are consistent and promising in understanding the phenomenon. However, it must be recognized that the effect of the third direction on convection was not considered in this work, so a three-dimensional study could be a natural consequence of this work in order to really analyze the different structures and aspects of convection.

\section{Acknowledgements}

We would like to thank Professors Mahamoud, Beye and Mbow for their encouragement.

\section{References}

[1] Saied, N.H. (2005) Natural Convection in a Square Porous Cavity with an Oscillating Wall Temperature. Arabian Journal for Science and Engineering, 31, 35-46. 
[2] Nield, D.A. and Bejan, A. (2006) Convection in Porous Media. 3rd Edition, Springer Science and Business Media, New York, 640 p.

[3] Kaviany, M. (1995) Principles of Heat Transfer in Porous Media. Springer, New York. https://doi.org/10.1007/978-1-4612-4254-3

[4] Vafai, K. (2005) Handbook of Porous Media. 2nd Edition, CRC Press, New York, 784.

[5] Ingham, D.B. and Pop, I. (2005) Transport Phenomena in Porous Media III. Elsevier, Oxford, $450 \mathrm{p}$.

[6] Schaladaw, S., Patterson, J.C. and Street, R.L., (1989) Transient Flow in a side-Heated Cavity at high Rayleigh Number: A Numerical Study. Journal of Fluid Mechanics, 200, 121-148. https://doi.org/10.1017/S0022112089000595

[7] Oztop, H.F., Oztop, M. and Varol, Y. (2009) Numerical Simulation of Magneto-Hydrodynamic Buoyancy-Induced Flow in a Non-Isothermally Heated Square Enclosure. Communications in Nonlinear Science and Numerical Simulation, 14, 770-778. https://doi.org/10.1016/j.cnsns.2007.11.005

[8] Kalabin, E.V., Kanashina, M.V. and Zubkov, P.T. (2005) Natural-Convective Heat Transfer in a Square Cavity with Time-Varying Side-Wall Temperature. Numerical Heat Transfer, Part A, 47, 621-631. https://doi.org/10.1080/10407780590896853

[9] Kazmierczak, M. and Chinoda, Z., (1992) Buoyancy-Driven Flow in an Enclosure with Time Periodic Boundary Conditions. International Journal of Heat and Mass Transfer, 35, 1507-1518. https://doi.org/10.1016/0017-9310(92)90040-Y

[10] Varol, Y., Oztop, H.F. and Pop, I. (2008) Numerical Analysis of Natural Convection for Porous Rectangular Enclosure with Sinusoidal Varying Temperature Profile on the Bottom Wall. International Communication in Heat and Mass Transfer, 35, 56, 64.

[11] Deng, Q.H. and Chang, J.J. (2008) Natural Convection in a Rectangular Enclosure with Sinusoidal Temperature Distribution on Both Side Walls. Numerical Heat Transfer, Part A, 54, 507-524. https://doi.org/10.1080/01457630802186080

[12] Baytas, A.C. and Pop, I. (2002) Free Convection in a Square Porous Cavity using a Thermal no Equilibrium Model. International Journal of Thermal Sciences, 41, 861-870.

[13] Kimura, S., Vynnycky, M. and Alavyoon, F. (1995) Unicellular Natural Circulation in a Shallow Horizontal Porous Layer Heated from below by a Constant Flux. Journal of Fluid Mechanics, 294, 231-257. https://doi.org/10.1017/S0022112095002874

[14] Darcy, H.P.C. (1856) Les fontaines publiques de la ville de Dijon. Victor, Dalmont, Paris.

[15] Moya, S.L. and Ramos (1987) Numerical Study of a Natural Convection in Tilted Rectangular Porous Material. International Journal of Heat and Mass Transfer, 30, 741-756.

[16] Sheremet, M.A. and Pop, I. (2014) Natural Convection in Square Porous Cavity with Sinusoidal Temperature Distributions in Both Side Walls Filled with a Nanofluid: Buongiorno's Mathematical Model. Transport in Porous Media, 105, 411-429. https://doi.org/10.1007/s11242-014-0375-7

[17] Bejan, A. (1979) On the Boundary Layer Regime in a Vertical Enclosure Filled with a Porous Medium. Letters in Heat and Mass Transfer, 6, 93-102. 


\section{Nomenclature}

$g$ gravitational acceleration $\mathrm{m} \cdot \mathrm{s}^{-2}$

$K$ permeability of the porous medium $\mathrm{m}^{2}$

$H$ cavity Height $\mathrm{m}$

$\mathrm{Nu}$ local Nusselt number

$\overline{\mathrm{Nu}}$ Average Nusselt number

$R a$ Rayleigh-Darcy number

$T$ fluid temperature $\mathrm{K}$

$T_{C}$ temperature of the cold walls $\mathrm{K}$

$T_{H}$ temperature of the hot wall

$u, v$ velocity components along $\mathrm{x}$ and $\mathrm{y}$-axes, respectively $\mathrm{m} \cdot \mathrm{s}^{-1}$

$x, y$ Cartesian coordinates $\mathrm{m}$

$A_{r}$ Amplitude of temperature

$x^{*}, y^{*}$ non-dimensional Cartesian coordinates

$T^{*}$ non-dimensional temperature

$c_{f}$ Thermal capacity of fluid $\mathrm{J} \cdot \mathrm{kg}^{-1} \cdot \mathrm{K}^{-1}$

$c_{s}$ Thermal capacity of porous media $\mathrm{J} \cdot \mathrm{kg}^{-1} \cdot \mathrm{K}^{-1}$

$t$ Time s

$t^{*}$ Non-dimensional time

\section{Greek Letters}

$\alpha$ Thermal diffusivity coefficient $\mathrm{m}^{2} \cdot \mathrm{s}^{-1}$

$\beta$ Coefficient of thermal expansion $\mathrm{K}^{-1}$

$v$ Kinematic viscosity $\mathrm{m}^{2} \cdot \mathrm{s}^{-1}$

$\psi$ Stream function $\mathrm{m}^{2} \cdot \mathrm{s}^{-1}$

$\psi^{*}$ Non-dimensional stream function

$\rho_{f}$ Density of fluid $\mathrm{kg} \cdot \mathrm{m}^{-3}$

$\rho_{s}$ Density of porous media $\mathrm{kg} \cdot \mathrm{m}^{-3}$

\section{Subscript}

C: cold, H: hot, f: fluid, s: solid min minimum value max maximum value

\section{Superscript}

${ }^{*}$ non-dimensional variables

-Average value 
Submit or recommend next manuscript to SCIRP and we will provide best service for you:

Accepting pre-submission inquiries through Email, Facebook, LinkedIn, Twitter, etc. A wide selection of journals (inclusive of 9 subjects, more than 200 journals)

Providing 24-hour high-quality service

User-friendly online submission system

Fair and swift peer-review system

Efficient typesetting and proofreading procedure

Display of the result of downloads and visits, as well as the number of cited articles Maximum dissemination of your research work

Submit your manuscript at: http://papersubmission.scirp.org/

Or contact ojfd@scirp.org 